Л., «Медицина», 1978., 280 с.

2. Котляр Д.Л., Функциональное состояние организма лётчиков вертолётов морской авиации и направления его оптимизации, Саратовский научно-мед журнал, том 5, № 2, 2009, c. 215-217.

3. Đố Văn Hàm, Giáo trình Sức khỏe nghề nghiệp, NXB Y học, 2007.

4. Nguyễn Liễu (2010), "Nghiên cứu thực trang ô nhiếm môi trường lao động và sức khỏe bệnh tât của công nhân tại một số nhà máy xí nghiệp quổc phòng", Y học lao động và vệ sinh môi trường, số 13.
5. ACGIH (1991), "Applied occupational enviromental hygiene", Elsevier sciene Inc. New York.

6. Hartmut Ising, Wolfgang Babisch, Barbara Kruppa.Noise-induced endocrine effects and cardiovascular risk, Noise \& Health, 1999. Vol. 1, №. 4. P. 37- 48.

7. Lê Trung (2000), Bệnh nghề nghiệp, tập III trang 335-343.

8. Колганов А.В., Марьенко Л.В., Гигиена труда и профессиональные заболевания., 1977., № 9 (сентябрь)., С. 41-43., ISSN 0016-9919.

\title{
VAI TRÒ CỦA X-QUANG THƯỜNG QUY TRONG CHẨN ĐOÁN THOÁI HOÁ KHỚP GỐI TIÊN PHÁT
}

\section{TÓM TẮT}

Nghiên cứu được tiến hành trên 76 bệnh nhân thoái hoá khớp gối tiên phát, giai đoạn II, III, đến khám và điều trị tại bệnh viện Việt. Mục tiêu: mô tả một số đặc điểm hình ảnh X-quang thường quy của bệnh nhẩn thoái hoá khớp gối tiên phát. Pháp nghiên cứu: Bênh nhân được chup X-quang khớp gối theo hai bình diện thẳng và nghiểng với tư thế đứng có tỳ trọng lượng. Mức độ thoái hoá khớp được đánh giá theo tiêu chuẩn Kellgren- Lawrence, mô tả tổn thương theo thang điểm của OARSI. Kết quả: Gai xương có ở tất cả bệnh nhân. Hẹp khe khớp, đặc xương dưới sun và biến dang đầu xương lần lượt chiếm tỷ lệ $82,6 \%, 76,1 \%$ và $60,9 \%$. Nhóm thoái hoá đô II có điểm từ 1,5-2 theo OARSI, trong khi đó đối với nhóm thoái hoá độ III, số điểm từ 2,2-2,7. Kết luận: Mặc dù việc sử dụng rộng rãi phương pháp siêu âm khớp và chụp cắt lớp hoặc cộng hưởng từ trong thực hành lâm sàng, song chụp $X$ quang khớp gối thổng thường vẫn là tiêu chuẩn "vàng" để đánh giá tình trang thoái khớp gối.

Tư khoá: Thoái hoá khớp gối, X-quang khớp gối, gai xương

\section{SUMMARY \\ ROLE OF ROUTINE X-RAY IN DIAGNOSIS OF PRIMARY KNEE OSTEOARTHRITIS}

The study was conducted on 76 patients with primary knee osteoarthritis, stages II, III, who came for examination and treatment at VietDuc Hospital. Objectives: Describe some routine X-ray imaging characteristics of the patients. primary knee osteoarthritis. Method: The patient was X-rayed of the knee joint in both posteroanterior lateral and view

${ }^{1}$ Đại Học Y Hà Nội,

${ }^{2}$ Bênh viên HN Việt Đức

Chịu trách nhiệm chính: Dương Đình Toàn

Email: duongdinhtoan@hmu.edu.com

Ngày nhận bài: 23.8.2021

Ngày phản biên khoa họ: 14.10.2021

Ngày duyệt bài: 25.10.2021

\section{Dương Đình Toàn" ${ }^{1,2}$}

with a standing position with weight bearing. The degree of osteoarthritis was assessed according to the Kellgren-Lawrence criteria, describing the damage according to the OARSI scale. Results: Bone spurs were present in all patients. Joint space, subchondral bone thickening and bone head deformity accounted for $82.6 \%, 76.1 \%$ and $60.9 \%$, respectively. The grade II degenerative group has a score of 1.5-2 according to OARSI, while for the group with grade III degeneration, the score is from 2.2-2.7. Conclusion: Despite the widespread use of joint ultrasonography and magnetic resonance tomography in clinical practice, conventional radiography of the knee remains the "gold" standard in the contemporary assessment of osteoarthritic knee.

Key words; radiography, osteoarthriti, bone spurs

\section{I. ĐẶT VẤN ĐỀ}

$X$-quang thường quy vẫn là tiêu chuẩn "vàng" trong đánh giá thoái hóa khớp gối (THKG). X-quang là hình chiếu hai chiều của cấu trúc khớp gối ba chiều. Những thay đổi trên phim X-quang bao gồm hẹp khe khớp, hình thành các gai xương, đặc xương dưới sụn và u nang, biến dạng đầu xương. Những thay đổi này xảy ra trong các giai đoạn phát triển khác nhau của bệnh thoái hóa khớp và được phản ánh trong các thang điểm đánh giá bán định lượng. Một trong những thang điểm được sử dụng phồ biến nhất là thang điểm được tạo ra bởi Kellgren và Lawrence vào năm 1957, trải qua nhiều lần sửa đổi theo thời gian. Một atlas của Hiệp hội Nghiên cứu viêm thoái hoá khớp Quốc tễ (OARSI) đưa ra một cách tiếp cận khác để đánh giá mang tính định lượng, chi tiết hơn, dựa trên khảo sát các hình ảnh thoái hoá ở các vùng khác nhau của khớp gối. Đo khoảng cách giữa ranh giới xương đùi và xương chày là phương pháp định lượng phổ biến nhất để đánh giá thoái hóa khớp gối. Một trong những nhược điểm chính 
của chụp X-quang thông thường là sự biến đổi của hình ảnh tùy thuộc vào vị trí khác nhau của khớp trong không gian. X-quang chụp ở tư thế gối gấp cung cấp thông tin đáng tin cậy về không gian khe khớp ở bệnh nhân thoái hóa khớp gối mức độ trung bình. X-quang chụp ở tư thế đứng, chân chịu lực đánh giá được mức độ hẹp khe khớp. Mục tiêu của nghiên cứu này nhằm khảo sát, đánh gía các đă điểm tổn thương thoái hoá trên phim X-quang thường quy.

\section{II. ĐỐI TƯợNG VÀ PHƯƠNG PHÁP NGHIÊN CỨU}

2.1. Thời gian nghiên cứu: $10 / 2015$ 4/2018.

2.2. Địa điểm nghiên cứu: Viện chấn thương chỉnh hình Bệnh viện Hữu Nghị Việt Đức

2.3. Đối tượng nghiên cứu: Là những bệnh nhân có THKG tiên phát, được chẩn đoán theo tiêu chuẩn của hội Khớp học Hoa Kỳ (ACR), giai đoạn II, III theo Kellgren-Lawrence,

Tất cả bệnh nhân được chụp X-quang khớp gối hai bình diện thẳng và nghiêng, tư thế đứng, khớp gối chịu tải

Đánh giá mức độ thoái hoá khớp dựa theo tiêu chuẩn của Kellgren-Lawrence [1]

Đánh giá đặc điểm tổn thương dựa theo tiêu chuẩn của OARSI [2]

2.4. Thiết kế nghiên cứu: Nghiên cứu mô tả cắt ngang

\section{KẾT QUẢ NGHIÊN CỨU}

3.1. Đặc điểm đối tượng nghiên cứu

Bảng 3.1. Phân bố bệnh theo tuổi, giới $(n=76)$

\begin{tabular}{|c|c|c|c|}
\hline \multicolumn{2}{|c|}{$(\mathbf{n = 7 6})$} \\
\hline \multirow{3}{*}{ Đặc điếm đối tượng } & $\mathbf{n}$ & $\mathbf{\%}$ \\
\cline { 2 - 4 } & $40-49$ & 8 & $10,5 \%$ \\
\cline { 2 - 4 } & $50-59$ & 47 & $61,9 \%$ \\
\hline
\end{tabular}

\begin{tabular}{|c|c|c|c|}
\hline \multirow{2}{*}{ Giới } & Nam & 24 & 31,5 \\
\cline { 2 - 4 } & Nữ & 52 & 68,5 \\
\hline
\end{tabular}

Nhân xét: Độ tuối trung bình là 54,82 (4669), nhóm tuổi gặp nhiều nhất là $50-59$, chiếm $63 \%$. Nữ nhiều hơn nam, với tỷ lệ là $2: 1$.

Bảng 3.2. Phân bố bệh nhân theo chi số BMI ( $(n=76)$

\begin{tabular}{|c|c|c|c|}
\hline Phân loại & $\mathbf{B M I} \mathbf{( k g / \mathbf { m } 2 )}$ & $\mathbf{n}$ & $\mathbf{\%}$ \\
\hline Thiếu cân & $<18.5$ & 0 & 0 \\
\hline Bình thường & $18.5-22.9$ & 15 & 19,7 \\
\hline Thừa cân & $23-24.9$ & $\mathbf{3 4}$ & $\mathbf{4 4 , 7}$ \\
\hline Béo phì độ I & $25-29.9$ & $\mathbf{2 5}$ & $\mathbf{3 2 , 9}$ \\
\hline Béo phì độ II & $\geq 30$ & 2 & 2,7 \\
\hline
\end{tabular}

Nhấn xét: Từ bảng 3.2 cho thấy, nhóm thừa cân và béo phì chiếm $77,6 \%$, trong đó chủ yếu là thừa cân và béo phì độ $\mathrm{I}$.

3.2. Đặc điểm tổn thương trên phim XQ

Bảng 3.3. Mức độ THKG trên XQ theo theo Kellgren-Lawrence $(n=76)$

\begin{tabular}{|c|c|c|}
\hline Mức độ̣ THKG & $\mathbf{n}$ & $\%$ \\
\hline Độ I & 0 & 0,0 \\
\hline Độ II & 28 & 36,8 \\
\hline Độ III & 48 & 63,2 \\
\hline Độ IV & 0 & 0,0 \\
\hline
\end{tabular}

Nhân xét: trong nhóm nghiên cứu, phân lớn bệnh nhân là THKG độ III, chiếm tỷ lệ 63,2\%. Trong khi đó, THKGđộ İ chỉ chiếm 36,8\%.

Bảng 3.4. Hinh ảnh tốn thương trên XQ $(n=76)$

\begin{tabular}{|c|c|c|c|c|}
\hline & $\begin{array}{c}\text { Gai } \\
\text { xương }\end{array}$ & $\begin{array}{c}\text { Hẹp } \\
\text { khe } \\
\text { khớp }\end{array}$ & $\begin{array}{c}\text { Đặc } \\
\text { xướng } \\
\text { dưới sụn }\end{array}$ & $\begin{array}{c}\text { Biến dạng } \\
\text { đâuu } \\
\text { xương }\end{array}$ \\
\hline $\mathrm{N}$ & 46 & 38 & 35 & 28 \\
\hline$\%$ & 100 & 82,6 & 76,1 & 60,9 \\
\hline
\end{tabular}

Nhân xét: Gai xương có ở tất cả bệnh nhân. Hepp khe khớp, đặc xương dưới sụn và biến dạng đầu xương lần lượt chiếm tỷ lệ $82,6 \%, 76,1 \%$ và $60,9 \%$.

Bảng 3.5. Mức độ THKG trên XQ theo OARSI $(n=76)$

\begin{tabular}{|c|c|c|c|c|c|c|}
\hline \multirow{2}{*}{$\begin{array}{c}\text { Mức độ } \\
\text { THKG }\end{array}$} & \multicolumn{4}{|c|}{ Gai xương } & \multicolumn{2}{|c|}{ Hẹp khe khớp } \\
\hline & MCT & MCN & LCT & LCN & $\begin{array}{l}\text { Khoang } \\
\text { trong }\end{array}$ & $\begin{array}{c}\text { Khoang } \\
\text { ngoài }\end{array}$ \\
\hline Độ & & & 2 & & $2,2 \pm 0,4$ & $1,9 \pm 0,23$ \\
\hline Độ III $(n=48)$ & $2,5 \pm 0,5$ & $2,2 \pm 0,7$ & $2,3 \pm 0,35$ & $2,1 \pm 0,43$ & $2,7 \pm 0,29$ & $2,4 \pm 0,25$ \\
\hline
\end{tabular}

Ghi chú: MCT: mâm chây trong. MCN: Mâm chây ngoài, LCT: lồi cầu trong, LCN: Lồi câu ngoài

Nhận xét: Phân bố hình ảnh gai xương, hẹp khe khớp đối với THKG ta thấy, nhóm bệnh nhân THKG độ II có điểm từ 1,5-2, , trong khi đó đối với nhóm THKG độ III, số điểm từ 2,2-2,7

\section{BÀN LUÂ̂N}

Thoái hoá khố (THK) là bệnh phổ biến dẫn đến đau và giảm chức năng khớp ở mức độ khác nhau và giảm chất lượng cuộc sống. THK là một quá trình diễn ra từ từ, tiến triển và gây tàn phế với tần suất cao ở người. Nó ảnh hưởng đến 12$15 \%$ dân số trưởng thành. $80 \%$ người từ 75 tuổi trở lên bị THK. [3]

Gần đây, nhiêu ý kiến phổ biến cho rằng THK chỉ là kết quả của sự hao mòn sụn khớp, ý kiến này đã được xem xét lại. Hiện nay, THK được mô tả là một tình trạng ảnh hưởng đến tất cả các cấu trúc của khớp - một bệnh của toàn bộ cơ quan. Điều này bao gồm xương, sụn hyalin, bao 
khớp, sụn chêm, dây chằng, bao hoạt dịch và cơ quanh khớp [4]

Thoái hóa khớp gối biểu hiện phổ biến nhất với một hoặc nhiêu đặc điểm gồm sưng, đau, cứng khớp, mất chức năng khớp, tiếng kêu lục cục, giảm biên độ vận động khớp.

Những thay đổi về cấu trúc của khớp gối bao gồm sự hình thành các các gai xương, giảm hyalin hóa sụn, đặc xương dưới sụn, u nang dưới sun, tràn dịch khớp và viêm màng hoạt dịch. Thoái hóa khớp gối thường đi kèm với sự thay đổi trục của đầu gối. Những thay đổi này là chủ đề của các phương pháp chẩn đoán hình ảnh.

Tuy nhiên mức đô nghiêm trong của các triêu chứng không phải lúc nào cũng tương ứng với những thay đổi cấu trúc khớp được đánh giá bằng hình ảnh. Do đó, trong quá trình chẩn đoán và điều trị, cần tiếp cận tống quát hơn để đánh giá mức độ nghiêm trọng của bệnh.

Chụp X-quang thường quy vẫn là tiêu chuẩn "vàng" để đánh giá những thay đổi cấu trúc liên quan đến THK gối. Đo khoảng cách khe khớp bằng $X$ quang là phương pháp hợp lý nhất để đánh giá tình trạng mất sụn khớp. Các thay đổi khác trên phim chụp $X$-quang bao gồm sự hiện diện của các gai xương xương, xơ xương dưới sụn và u nang dưới sụn.

Tia $X$ đại diện cho khái niệm hai chiều về cấu trúc khớp ba chiều của khớp gối. Thực tế này tao ra các điều kiện tiên quyết cho các biến thể hình ảnh tùy thuộc vào vị trí chung trong không gian

Chup X-quang gối tư thế thẳng (trước sau) ở tư thế bênh nhân đứng duỗi thẳng chân và chiu trọng lực cơ thể. Đây là phương pháp được nhiều người sử dụng. Tuy nhiên từ các kết quả nghiên cứu gần đây chỉ ra rằng chụp X-quang khớp gối ở tư thế gối gấp cố định một góc độ nào đó sẽ tăng độ nhạy đối với đánh giá khớp gối thoái hoá ở giai đoạn II và III. Khi chụp X-quang, khớp gối chịu tải sẽ cho kết quả chính xác hơn về mức độ hẹp khe khớp, cũng chính là mức độ tổn thương sụn khớp phần sau của lồi cầu đùi.

\begin{tabular}{|c|c|c|c|c|c|c|}
\hline $\begin{array}{c}\text { Vị trí đánh } \\
\text { giá }\end{array}$ & $\begin{array}{c}\text { Mâm châyy } \\
\text { trong }\end{array}$ & $\begin{array}{c}\text { Mâm chầy xương } \\
\text { ngoài }\end{array}$ & $\begin{array}{c}\text { Lô̂i câu } \\
\text { trong }\end{array}$ & $\begin{array}{c}\text { Lôi câu } \\
\text { ngoài }\end{array}$ & $\begin{array}{c}\text { Khoanp khe khớp } \\
\text { trong }\end{array}$ & $\begin{array}{c}\text { Khoang } \\
\text { ngoài }\end{array}$ \\
\hline Điếm & $0-3+$ & $0-3+$ & $0-3+$ & $0-3+$ & $0-3+$ & $0-3+$ \\
\hline
\end{tabular}

Tập atlas của Hiệp hội Nghiên cứu về viêm thoái hoá khớp Quốc tế (OARSI) đưa ra môtt cách tiếp cận khác để đánh giá tình trạng thoái hóa khớp gối dựa vào mức độ tổn thương khớp tai nhiều vị trí khác nhau. Phương pháp này là bán định lượng, vì khe khớp châyy đùi và gai xương được diển giải riêng biệt cho từng vùng của khớp gối, với điểm từ 0 đến $3(0=$ không
Hầu hết các hình ảnh có thể thu được trên phim chụp thẳng của khớp gối ở tư thế chụp Lyon-Schuss với góc nghiêng $10^{\circ}$ của chùm tia $X$. Nếu phim chụp đúng tiêu chuẩn, có thể sẽ mang lại hai lợi thế so với tư thế thông thường, đó là thứ nhất khi gối ở tư thế gấp có nhiều khả năng bộc lộ sự mất sụn khu trú ở phía sau của lồi cầu xương đùi [5]. Thứ hai, khe khớp được chụp theo hướng song song hoắc gần song song với chùm tia $X$. Những ưu điểm này cung cấp một phương pháp chính xác hơn trong việc đánh giá các thay đổi cấu trúc và theo dõi chúng theo thời gian.

Chụp X-quang gối tư thế nghiêng thường bị đánh giá thấp hơn trong đánh giá thoái hóa khớp gối. Phim nghiêng cho một cái nhìn toàn cảnh khớp gối. Các đường viền của lồi cầu đùi và mâm chày hiện rõ. Phim nghiêng cho phép đánh gía khớp chè đùi, không những nhìn rõ các gai xương do thoái hoá mà còn có thể phát hiện những bệnh lý của xương bánh chè

Phương pháp X-quang bán định lượng

Thang điểm Kellgren-Lawrence được sử dụng rộng rãi để đánh giá mức độ thoái hóa khớp gối [1].

\section{Bảng điểm Kellgren-Lawrence}

\begin{tabular}{|c|c|}
\hline Giai đoạn & Mô tả \\
\hline 0 & Không có dấu hiệu của thoái hoá khớp \\
\hline 1 & $\begin{array}{l}\text { Đặc xương dưới sụn, chưa có gai } \\
\text { xương, chưa hẹp khe khớp }\end{array}$ \\
\hline 2 & $\begin{array}{l}\text { Có gai xương nhỏ và có thể có hẹp } \\
\text { khe khớp }\end{array}$ \\
\hline 3 & $\begin{array}{l}\text { Xuất hiện nhiêu gai xương, hẹp khe } \\
\text { khớp rõ, đặc xương dưới sưn, có thể } \\
\text { biến dạng đầu xương }\end{array}$ \\
\hline 4 & $\begin{array}{c}\text { Nhiêu gai xương lớn, khe khớp hẹp } \\
\text { nhiêu, biến dạng khơp gối }\end{array}$ \\
\hline
\end{tabular}

Những hạn chế chính của thang điểm Kellgren-Lawrence bao gồm 1) nâng tầm quan trọng đối với gai xương; 2) không nhạy đối với những thay đổi tại khớp; 3 ) thiếu đánh giá đầy đủ về không gian khớp. [1]

có; $1=$ nhe; 2 = trung bình; $3=$ năng). Cách tính điểm này làm tăng độ nhạy của $X$-quang [2].

\section{KẾT LUẬN}

Mặc dù việc sử dụng rộng rãi phương pháp siêu ẩm khớp và chụp cắt lớp hoặc cộng hưởng từ trong thực hành lâm sàng, song chụp $X$ quang khớp gối thông thường vẫn là tiêu chuẩn "vàng" 
để đánh giá tình trạng thoái khớp gối. Nó là một hình chiếu hai chiều của các cấu trúc khớp ba chiều. Điều này tạo ra một điều kiện tiên quyết cho các biến thể của hình ảnh ở các vị trí khác nhau của không gian khớp. Chụp X-quang ở tư thế gập gối cố định cung cấp thông tin đáng tin cậy về khe khớp ở bệnh nhân thoái hóa khớp gối mức độ trung bình. Để khách quan hóa kêt quả chụp $X$ quang thông thường trong thực hành và nghiên cứu lâm sàng, các phương pháp định lượng và bán định lượng được sử dụng để đánh giá thoái hóa khớp gối. Thang điểm của Kellgren và Lawrence được sử dụng rộng rãi trong hệ thống 5 điểm để đánh gía thoái hoá khớp gối. Tuy nhiên, cần lưu ý rằng những triệu chứng của bện không phải lúc nào cũng tương ứng với những thay đổi cấu trúc được đánh giá bởi hình ảnh Xquang. Do đó, trong quá trình chẩn đoán và điều trị cần có phương pháp tiếp cận phối hợp để đánh giá chính xác mức độ nghiêm trọng của bệnh.

\section{TÀI LIÊU THAM KHẢO}

1 Kellgren JK, Lawrence JS. Radiological assessment of osteoarthritis. Ann Rheum Dis 1957; 16:494-501

2 Culvenor, Adam G., et al. "Defining the presence of radiographic knee osteoarthritis: a comparison between the Kellgren and Lawrence system and OARSI atlas criteria." Knee Surgery, Sports Traumatology, Arthroscopy 23.12 (2015): 3532-3539.

3 Arden, Nigel, and Michael C. Nevitt. "Osteoarthritis: epidemiology." Best Practice \& Research Clinical Rheumatology 20, no. 1 (2006): 3-25.

4 Loeser, Richard F., et al. "Osteoarthritis: a disease of the joint as an organ." Arthritis \& Rheumatism 64.6 (2012): 1697-1707.

5 Messieh SS, Fowler PJ, Munro T. Anteroposterior radiographs of the osteoarthritic knee. J Bone Joint Surg Br 1990;72(4):639-640

6 LaValley, Michael P., et al. "The lateral view radiograph for assessment of the tibiofemoral joint space in knee osteoarthritis: its reliability, sensitivity to change, and longitudinal validity." Arthritis \& Rheumatism 52.11 (2005): 3542-3547

\section{ĐÁNH GIÁ SỰ HÀI LÒNG CỦA NGƯờI BÊNH ĐỐI VỚI DİCH VỤ CHẨN ĐOÁN HİNH ẢNH TẠI BỆNH VIỆN ĐA KHOA TRUNG TÂM TIỀN GIANG NĂM 2021}

\section{TÓM TẮT}

Đặt vấn đề: chẩn đoán hình ảnh ( $\mathrm{CĐHA)} \mathrm{là} \mathrm{một}$ thành phần của dịch vu y tế, với tư cách là nhà cung cấp dịch vụ, các cơ sở cung cấp dịch vụ CĐHA cần hiểu chất lượng dịch vụ mà mình cung cẩp, về sự hài lòng của khách hàng và các vấn đề liên quan. Mục tiêu: Mô tả sư hài lòng của người bênh và bác sĩ lậm sàng đối với dịch vụ chẩn đoán hình ảnh của Bệnh viện Đa khoa Trung tâm Tiền Giang, năm 2021. Thiết kể nghiên cứu: mô tả cắt ngang. Kết quả: Nghiên cứu trên 280 người bệnh (NB) ghi nhân: Tỉ lệ hài lòng chung của người bệnh về dịch vụ chẩn đoán hình ảnh là $67,14 \%$. Hài lòng đối với từng yếu tố: yếu tố tin cậy đạt 75,36\%; yếu tố đáp ứng đạt Tỉ lệ 72,86\%; về nẳng lực phục vụ đạt 76,79\%; yểu tố hữu hinh đạt Tỉ lệ $74,64 \%$; yếu tố đồng cảm đạt 73,93\%. Kết luận: mức độ hài lòng của người bệnh khá cao, tuy nhiên cần thực hiện một số giải pháp nâng cao chất lượng dich vu CĐHA

Tư khóa: sự hài lòng, người bệnh (NB), chẩn đoán hình ảnh (CॄĐHA)

${ }^{1}$ Bệnh viện Đa khoa Trung tâm Tiền Giang Chịu trách nhiệm chính: Nguyễn Thị Bạch Tuyết Email: bachtuyettiengiang@gmail.com Ngày nhận bài: 16.8 .2021

Ngày phản biện khoa học: 11.10.2021

Ngày duyệt bài: 18.10.2021

\section{SUMMARY}

\section{THE SATISFACTION OF PATIENTS WITH THE DIAGNOSTIC IMAGING SERVICES OF TIEN GIANG CENTRAL GENERAL HOSPITAL IN 2021}

Background: Diagnostic imaging is a component of medical services, as service providers, the service providers need to understand the quality of the services they provide on customer satisfaction and related issues. Objective: Describe the satisfaction of patients and clinicians with the diagnostic imaging services of Tien Giang Central General Hospital in 2021. Methods: Cross-sectional description. Results: A study on 280 patients recorded: The overall satisfaction rate of patients with imaging services was $67.14 \%$. Satisfied with each factor: reliability factor reached $75.36 \%$; response factor reached the rate of $72.86 \%$; service capacity reached $76.79 \%$; tangible elements reached the rate of $74.64 \%$; empathy factor reached $73.93 \%$. Conclusion: Patient's satisfaction is quite high, however, it is necessary to implement some solutions to improve the quality of diagnostic imaging services.

Keywords: satisfaction, patients, diagnostic imaging.

\section{I. ĐẶT VẤN ĐỀ}

Sự hài lòng của khách hàng đối với cơ sở y tế hiện nay đã trở thành tiêu chí quan trọng trong việc đánh giá chất lượng bệnh viện theo tiêu chí 